\title{
Biology and Mass Rearing Studies of Eucanthecona furcellata Wolf. (HEMIPTERA: PENTATOMIDAE) a Potential Polyphagous Predator and its Effect on Field Population of White Slug Caterpillar, Parasa philepida in Cabadbaran, Agusan del Norte, Philippines
}

\author{
Vivencio C. Gallego, Ruby T. Escalona \\ and Joana M.S. Ferreira ${ }^{1}$ )
}

\begin{abstract}
The biology and mass rearing of Eucanthecona furcellata Wolf, a polyphagous predator, was studied under laboratory conditions.

The predator has a total life cycle (egg to adult) of 46.25 days. The egg hatched 6 days after laying. The nymphs undergo seven instars with each stage ranging from $2.0-2.35$ days.

Mass-rearing techniques, effect of field releases and other ecological factors on pest population as well as other biological informations are also described.
\end{abstract}

\section{INTRODUCTION}

Limacodids are important coconut pests in the Philippines. The most prominent species found in the country are Parasa philepida, Thosea philippina and Setora oitens. Larval stages of the pest are the ones destructive. The larva feeds on the leaflets. In severe cases, only the midrib is left. The damage level range from $25-85 \%$. In areas where the pest has been established for a Iong time, as was the case in Cabadbaran, Agusan del Norte, reduction in yield is almost $100 \%$.

The slug caterpillar group are found to be rich in natural enemies. One of the most promising is the Eucanthecona fuccellata, a polyphagous predator. It was reported as potential predator of several leaf eating lepidopter as in Sumatra, Thailand and Asean countries (de Chenon, 1988; Napompeth,1989,1990).

\section{OBJECTIVES}

In view of the potential of the predator as a biocontrol agent on limacodid pests of coconut, mass rearing and biological studies were conducted to obtain more information on the insect for its utilization as an important control factor in limacodid pest management.

\section{MATERIALS AND METHODS}

The biology of E. furcellata were studied under laboratory condition using 20 individuals at 37 degree centigrade and $87 \%$ relative humidity.

The longevity and fecundity of the adult stage of the predator as influenced by different sources of food and ratio of male and female was determined. Five sources of food were evaluated, which include larvae of coconut spike moth, Tirathaha cufivena; green slug caterpillar, Thosea philippina; white slug caterpillar, Parasa philepida; rhinoceros larvae, Oryctes rhinoceros and $100 \%$ honey solution. These food materials were made available to the predator ad libitum. The female: male ratio monitored were 1:1, 1:2 and 1:3.

\footnotetext{
${ }^{1}$ Science Research Specialist 11, Science Research Assistant Crop Protection Division, Davao Research Center, Philippine Coconut Authority and Chief Technical Adviser, FAO/UNDP Project PHI/86/004, respectively.
} 
The consumption of $4^{\text {th }}, 5^{\text {th }}, 6^{\text {th }}$ and $7^{\text {th }}$ nymphal instar and adult of E.furcellata was determined by feeding a batch of 10 individuals with 10 third instar larvae of green; slug caterpillar for a period of 8 hours of observation.

The ultraviolet light traps were used to monitor the population of slug caterpillar in the field. To study its effect on the attraction of E.furcellata in areas where they were, released and had established its population, light traps were set up from 6:00 P.M to 6:00 A.M at Cabadbaran, Agusan del Norte. The number of catch were monitored every hour for three nights. In one area, the predator was released a day before light trapping was conducted.

Mass rearing of the predator was mostly done on a trial and error basis, especially as to its food requirements and male: female mating ratio among other factors. The rearing method of E.furcellata developed under laboratory condition was a modification of that described in Thailand by Napompeth(1990).

Pest population, percentage leaf damage and harvestable nuts were monitored quarterly to determine the effect of field releases of the predator. Leaf number 14 of the coconut crown were cut off to determine pest population and the corresponding damage were taken from 15 leaflets of the sample frond. Harvest data was gathered from 3 harvestable bunches of the sample palms.

\section{RESULTS AND DISCUSSIONS}

I. Biological and Behavioral Studies.

Biology of the predator Eucantbecona furcellata Wolf. (HEMIPTERA : PENTATOMIDAE) was studied under laboratory condition. These include observation on its life cycle from egg to adult stage, and its behavior (Table 1)

Table 1. Life Cycle of Eucanthecona furcellata Wolf*/

\begin{tabular}{|l|c|}
\hline \multicolumn{1}{|c|}{ Stage } & No. of days \\
\hline Egg & 6.0 \\
$1^{\text {st }}$ instar & 2.0 \\
$2^{\text {nd }}$ instar & 2.0 \\
$3^{\text {rd }}$ instar & 2.2 \\
$4^{\text {th }}$ instar & 2.05 \\
$5^{\text {th }}$ instar & 2.05 \\
$6^{\text {th }}$ instar & 2.05 \\
$7^{\text {th }}$ instar & 2.35 \\
Adult $\quad 25.55$ \\
\hline \multicolumn{2}{|c|}{ Total } \\
\hline
\end{tabular}

-*/average of 20 individuals

a. $\quad$ Egg

The eggs are laid in clusters on the nylon mesh, first yellowish in color and turning dark brown to black as they mature. An egg cluster contains frorn 5 to 50 eggs. An individual female can lay from 100 to 350 eggs throughout its adult life. The egg hatches after 6 days. 


\section{b. Nymph}

The predator undergoes 7 nymphal instars with a total of 14.7 days. The change in nymphal instars can be easily identified by their exuviae. This first instar which last for 2 days measures $1-2 \mathrm{~mm}$ in length and tends to congregate in batches. They usually do not feed yet and can survive on water. The second instar is characterized by initial feeding on host. The nymphs measure $3-4 \mathrm{~mm}$ and also last for 2 days. The third instar measures $5-6 \mathrm{~mm}$ and starts to become active. They usually move around inside the feeding cage and last for 2.2 days. The $4^{\text {th }}$ instar nymphs measure $7-8 \mathrm{mrn}$ and last for 2.05 days. The sizes of the male and the female become distinct at this stage with the latter being slightly bigger and longer. The $5^{\text {th }}$ instar measures $9-10 \mathrm{~mm}$. and lasts for 2.05 days. It is at this stage where the wings start to develop. The nymphs are very active and feed voraciously on the host. The size of the male and the female become more pronounced at this stage. Cannibalism is also noticeable at this stage when food was insufficient. The $6^{\text {th }}$ instar ( 2.05 days $)$ is characterized by the half developed wings. It is at this stage where the predator can be released in the field for establishement. It measures from $16-18 \mathrm{~mm}$. The $7^{\text {th }}$ instar is characterized by almost developed wing parts. It usually measures from $19-20 \mathrm{~mm}$. and lasts for 2.35 days. The nymph feed on the larvae placed on the top of rearing cage by puncturing through the nylon mesh to the host body by using its long proboscis.

\section{c. Adult}

The adult when fully developed measures frorn $24-26 \mathrm{~mm}$. It is characterized by fully developed wing parts. The male is slightly smaller than the female. The adults usually start to mate 5 days after emergence. Egg laying commences three days after mating. The adult feeding behavior follows the same pattern as that of the nymphal stage.

\section{d. Cannibalism}

Cannibalism in laboratory cultures develop when there was overcrowding and limited food resources. Two days after the predator runs out of food, the males were the first to weaken and were usually fed upon by the females. The female usually insert their proboscis on the soft portion like the base of the legs of the male. Once it becomes vulnerable to feeding, 3 to 5 adults both male and female feed on it by inserting their proboscis on the ventral portion of the abdomen which is usually soft. The adult usually stays alive for 4 days only when totally starved. Older nymphal instar cannibalized younger instars when kept in the same cage.

\section{e. Adult Longevity and Fecundity as Influenced by Different Sources of Food}

Longevity and fecundity of the adult stage of the predator as influenced by different sources of food was determined. Longevity of the adult predator was measured by the number of days they stayed alive upon feeding on different food materials. Result showed that those fed with white slug caterpillar survived longer (28.9) days. This was followed by those fed with coconut spike moth larvae (24.5) and green slug caterpillar with 22.8 days but which was not significantly different from, those feeding on white slug caterpillar. The predators fed with rhinoceros larvae and $100 \%$ honey solution lived the shortest with 10.9 and 8.7 days respectively. (Table 2).

Fecundity of the predator as measured by the number of eggs laid showed that those fed with green slug caterpillar gave the highest number of eggs laid (170.3) although it does not differ significantly as compared to those fed with coconut spikernoth (167.7) and white slug caterpillar (111.8). Those fed with rhinoceros larvae and $100 \%$ honey solution gave the lowest number of eggs laid (10.9 and 8.7), respectively, which was significantly lower as compared to the above three food sources. 
Table 2. Adult longevity and fecundity of Eucanthecona furcellata Wolf as influenced by different sources of food.

\begin{tabular}{|l|c|c|}
\hline \multicolumn{1}{|c|}{ Food Source } & Fecundity* (no.of fertile eggs laid) & Longevity**/ (Days) \\
\hline Coconut spike catterpillar & $167.7 \mathrm{a}$ & $24.5 \mathrm{a}$ \\
White slug caterpillar & $111.8 \mathrm{a}$ & $28.9 \mathrm{a}$ \\
$100 \%$ honey & $1.5 \mathrm{~b}$ & $8.7 \mathrm{~b}$ \\
Green slug caterpillar & $170.3 \mathrm{a}$ & $22.8 \mathrm{a}$ \\
Rhinoceros larva & $1.7 \mathrm{~b}$ & $10.9 \mathrm{~b}$ \\
\hline
\end{tabular}

* Means, followed by the same letters are not significantly different from each other at $1 \%$ level (DMRT).

**Observation based on means of 25 female samples.

f. Fecundity of the predator as Influenced by Ratio of Male to Female

Fecundity of the predator as influenced by ratio of male to female was measured by the number of fertilized eggs laid by the female. Observation showed that the ratio 1:3 gave the most number of fertile eggs laid per female (300.9). This was followed by ratio 1:2 which gave the highest average number of eggs laid per female (338) but had a higher number of unfertilized eggs (97.8) (Table 3).

Table 3. Fecundity of $E$. furcellata as influenced by ratio of male to female*

\begin{tabular}{|rrr|rrr|rrr|}
\hline \multirow{2}{*}{ Ratio } & \multirow{2}{*}{$\begin{array}{c}\text { Total \# } \\
\text { eggs laid }\end{array}$} & \multirow{2}{*}{$\begin{array}{c}\text { Average } \\
\text { Female }\end{array}$} & \multicolumn{3}{|c|}{ Fertilized } & \multicolumn{3}{c|}{ Unfertilized } \\
\cline { 4 - 9 } & & & \multicolumn{1}{c|}{ no. } & \multicolumn{1}{c|}{$\%$} & Ave/F & no. & $\%$ & Ave/F \\
\hline $1: 1$ & 153.1 & 153.1 & 106 & 75.9 & 106 & 47.1 & 24.1 & 47.1 \\
$1: 2$ & 677.7 & 338 & 579.9 & 85.6 & 145.0 & 97.8 & 14.43 & 48.9 \\
$1: 3$ & 915.4 & 305 & 902.3 & 98.6 & 300.9 & 12.6 & 1.4 & 4.2 \\
\hline
\end{tabular}

*/ based on 20 samples per ratio.

\section{h. Consumption of E. furcellata}

Consumption rate was measured by the number of larvae consumed after 8 hours of feeding. Results on Table 4 showed that the fourth instar nymph consumes an average of 1.5 larva per day. The $5^{\text {th }}$ instar consumes 1.7 larva per day. The $6^{\text {th }}$ and $7^{\text {th }}$ nymphal instars at 2.2 and 3.1 larvae per day, respectively. The adult consumes the most number of larvae at 4.4. Younger instars were unable to consume one larva per day.

i. Phototropic reaction of the Predator

The predator, E. furcellata showed no phototropic reaction. In three nights of successive trapping, no predator was trapped. In one area where the release of the predator was done a day before trapping was conducted, again, there was no predator trapped in the light trap.

This result suggests that light trapping can still be done in areas with adult limacodid populations without detrimental effect to the established or newly released predator population as the latter was not attracted to light traps. 


\section{Mass Rearing}

The mass rearing technique of Eucanthecona furcellata Wolf. Was developed under laboratory condition. This technique was based on the biological studies previously undertaken.

This consists of the following steps (Figure 1):

1. A laying cage measuring $24 \times 24 \times 12$ inches made of stable fine nylon mesh was used. A ratio of 1 male: 3 female adults of the predator were introduced and maintained. They were allowed to mate and lay eggs on the nylon mesh. As many as 10 males and 30 females were maintained in one laying cage.

2. The adults were fed with white slug caterpillar when available. Other alternate hosts such as green slug and ramie serni-looper were also used when white slug is not available. A frozen larvae of the above hosts were kept in stock for feeding when field population goes down. These were thawed first before feeding. Preserved feeding materials were misted with water to prevent it from drying immediately.

3. The female laid their eggs on the surface of the nylon mesh and started to hatch 6 days after.

4. Newly emerged nymphs were collected by allowing thern to congregate on coconut leaflet put on top of the laying cages.

5. These $1^{\text {st }}$ instar nymphs were out inside a smaller round rearing nylon cage measuring 14" diameter and 20" long with wire structure. This is a critical stage in mass rearing; as older instar cannibalized younger instar when kept in the same cage. Only 50 individuals of the same nymphal stages were maintained in a cage to prevent cannibalism. The nymphs were fed with larva of slug caterpillar or its alternate host by putting it on top of the cage. The nymphs feed on the larva by puncturing through the nylon mesh to the host body by use of its long proboscis.

6. The nymphs were allowed to develop on this cage. When fully matured, they were sexed and put inside the mating/laying cages following the ratio of 1.3 male to female.

III. Preliminary Results of the Release of E. furcellata on Field Population of White Slug Caterpillar

A very dramatic decrease in population of the pest was observed six months after initial reiease of the predator (Table 5). Also an abnormally high rainfall that occurred during the second quarter of 1990 might have contributed to the control of pest population. It was observed that during rainy season more number of larvae fell from the crown which eventually died on the ground.

The successive releases of the predator during the $2^{\text {nd }}$ quarter of 1991 , combined with other factors, had apparently led to the decrease of the remaining population of the pest. It was Important to note that there was no more damage recorded during the 3rd quarter up to the present. Regular releases of the predator in different barangays of Cabadbaran is being undertaken with the objective of minimizing pest outbreaks.

Nut yield of the palms that had recovered was observed to double one year after recovery (Table 5). 


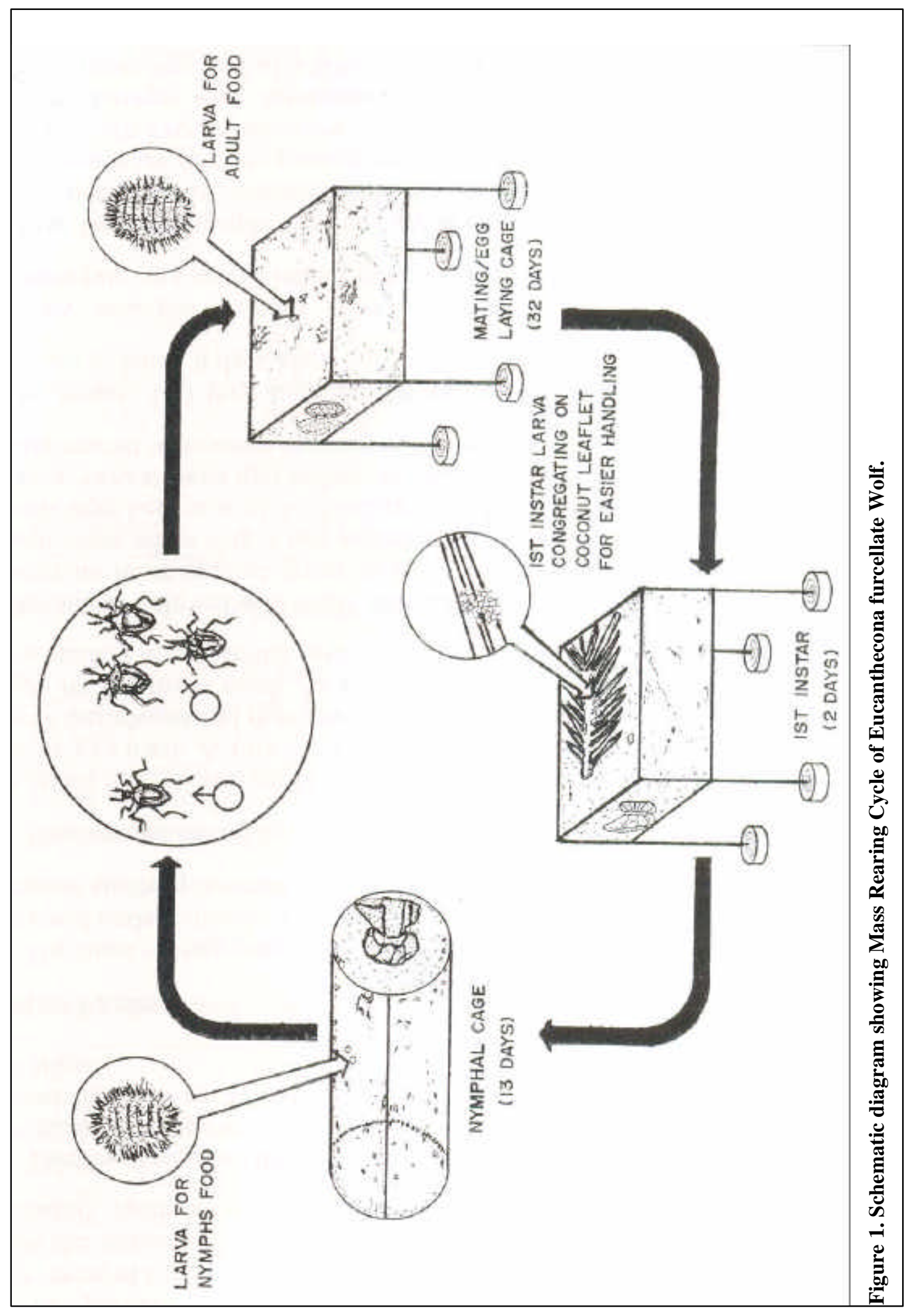


Table 4. Consumption of $E$. furcellata per day*/

\begin{tabular}{|c|c|c|c|c|c|}
\hline \multirow{2}{*}{ Individual } & & \multicolumn{3}{|c|}{ Nymphal Instar } & \multirow{2}{*}{ Adult } \\
\cline { 2 - 5 } & $4^{\text {th }}$ & $5^{\text {th }}$ & $6^{\text {th }}$ & $7^{\text {th }}$ & \\
\hline 1 & 1.8 & 1.8 & 2.3 & 3.2 & 5.3 \\
2 & 1.3 & 1.8 & 2.3 & 3.2 & 5.3 \\
3 & 1.8 & 1.8 & 1.8 & 3.2 & 4.0 \\
4 & 1.2 & 1.5 & 2.3 & 3.2 & 5.3 \\
5 & 1.2 & 1.8 & 2.3 & 3.6 & 4.0 \\
6 & 1.2 & 1.5 & 2.3 & 3.2 & 4.0 \\
7 & 1.2 & 1.8 & 2.3 & 3.2 & 4.0 \\
8 & 1.8 & 1.8 & 2.3 & 3.2 & 4.0 \\
9 & 1.3 & 1.8 & 2.3 & 3.2 & 4.0 \\
10 & 1.6 & 2.0 & 2.3 & 3.2 & 4.0 \\
\hline Mean & 1.5 & 1.7 & 2.2 & 3.1 & 4.4 \\
\hline
\end{tabular}

*) Third larval instar, green sluq caterpillar

Table 5. Population and damage level of $P$. philepida and nut yield of coconut and rainfall in Cabadbaran, Agusan de Note before, during and fater release of $\boldsymbol{E}$. Furcellata.

\begin{tabular}{|c|c|c|c|c|}
\hline YEAR/MONTH & $\begin{array}{c}\text { MEAN } \\
\text { POPULATION } \\
\text { (LARVA/FRON) }\end{array}$ & $\begin{array}{c}\text { DAMAGE } \\
\text { LEVEL } \\
(\%)\end{array}$ & $\begin{array}{c}\text { YIELD } \\
\text { (HARVESTABLE } \\
\text { NUTS/QUARTER }\end{array}$ & $\begin{array}{c}\text { RAINFALL (mm) } \\
\text { AVERAGE PER } \\
\text { MONTH }\end{array}$ \\
\hline 1983 & 34.7 & 69.3 & 5.8 & 476 \\
1984 & 6.2 & 54.0 & 6.1 & 579 \\
1985 & 14.8 & 4.8 & 5.7 & 536 \\
1986 & 16.1 & 30.9 & 5.9 & 668 \\
1987 & 51.3 & 50.8 & 6.0 & 460 \\
1988 & 31.0 & 53.9 & 6.3 & 567 \\
1989 & 10.7 & 56.5 & 6.1 & 560 \\
$19901^{\text {st }} \mathrm{Q}$ & 7.6 & 54.8 & 5.7 & 289 \\
$2^{\text {nd }} \mathrm{Q}$ & 39.9 & 64.8 & 5.3 & 1,061 \\
$3^{\text {rd }} \mathrm{Q}$ & 0.0 & 0.0 & 6.8 & 343 \\
$4^{\text {th }} \mathrm{Q}$ & 0.0 & 0.0 & 6.2 & 458 \\
$19911^{\text {st }} \mathrm{Q}$ & 0.0 & 0.0 & 10.5 & 513 \\
$2^{\text {nd }} \mathrm{Q}$ & 0.0 & 0.0 & 10.2 & 343 \\
$3^{\text {rd }} \mathrm{Q}$ & 0.0 & 0.0 & 11.4 & 331 \\
$4^{\text {th }} \mathrm{Q}$ & 0.0 & 0.0 & 11.4 & 559 \\
\hline
\end{tabular}




\section{LITERATURE CITED}

DE CHENON, R.A.. 1988. Technical Assistance Activities in Crop Protection at the Martha Oil Palm Researeh Center (Sept. 1987 -Sept. 1988). PT. Perkebunan VI-VII, Upset Benefiting Martha. P.O. Box 37, Pentagon Syntax, Sumptuary - Ultra.

NAPOMPETH, B 1989 Biological Control of Insect Pests and Weeds in Thailand. Bistro Spec. Publ. No. 36, 1989.

NAPOMPETH, B. 1990 Use of Natural Enernies to Control Agricultural pest in Thailand. Food and Fertilizer Technology Center Extension Bulletin no. 303. August 1990. 